\title{
An Analysis on the Effectiveness of the Tertiary Science Education Curriculum in the University of Nueva Caceres as Perceived by Science Teachers and Students
}

\author{
Lustiana Sari $^{1}$, Olivia M. Marfil ${ }^{2}$ and Dwi Sulisworo ${ }^{1}$ \\ ${ }^{1}$ Ahmad Dahlan University, Indonesia \\ ${ }^{2}$ University of Nueva Caceres, Philippines
}

\begin{abstract}
This study was conducted in line with the University of Nueva Caceres' (UNC) Research Agenda which provided foundation in improving new knowledge and conceptualizing new strategies to enhance the education process of students. This study was conducted to investigate the strengths, weaknesses, opportunities, and threats of the tertiary science education curriculum in UNC as perceived by science teachers and students. The research used interview and direct observation to gather pertinent data. The data were then analyzed using a conceptual framework. Through answers from interviews which are primarily from the observation of the participants then it categorized into strengths, weaknesses, opportunities, and threats. The analyzed data from students and observations of the researchers shows an evident weakness in the construction of the tertiary science education curriculum of the UNC. The following conclusions were made: the science education curriculum of UNC is not aligned to what is required by the K-12 curriculum in terms of teacher preparation, the science education curriculum of UNC affects the general performance of teachers to effectively instruct the students due to the failure of the curriculum to integrate related disciplines connected to Physical Science such as Mathematics, the science education curriculum also imposes a limitation of probable learning due to the lack of materials needed for some activities, there exists problems that affect the productivity of the students which are performance and skills-related, and there are ways to improve the current level of effectiveness of tertiary science curriculum through the integration of partnership possibilities with other universities and maintenance of current innovations.
\end{abstract}

Keywords: curriculum, SWOT analysis, education, tertiery school.

\section{Introduction}

As perceived by the researchers, the curriculum in science of the tertiary level at the University of Nueva Caceres (UNC) is currently facing problems which causes incompetence on the part of the students specializing in science and some college instructors teaching science subjects. The cause of this incompetence must be discovered as soon as possible for us to be able to find ample measures to remedy such problems. One of these causes is the failure of the science curriculum to enhance itself. Based on the observation of students, the science curriculum of UNC has stayed the same for four years despite suggestions to take measures to revise the curriculum. According to one, the science curriculum of UNC, specifically the roster of required subjects to be taken by students specializing in science is enough to prepare the would-be science teacher in the professional field of teaching. However, it was found out that it is not science-research oriented.

The researchers, as students specializing in science, were interested in this study because of the benefits it

will give to other students. This study will have a direct effect to the performance of the science department as reflected by the students' satisfaction to the science program, and to the interest of Science instructors to 
continue teaching their respective subjects. Furthermore, the existence of the incompetence of science education curriculum might also have a long term effect; like a continuous decrease on the number of enrollees which might lead to the dissolution of the program itself.

One of the thrusts of Department of Education (DepEd) is to strengthen the teaching of science. It is necessary to conduct this inquiry to find out how to strengthen the teaching of science in UNC. To attain alignment between the goal of DepEd and the goal of the UNC College of Education, a good curriculum must be established. The question remains; "Is the UNC Tertiary Science Education Curriculum well established?" As a discipline, science is one of the hardest to teach. This area of study involves a strategized combination of history, technical congruence, arithmetic, and practical application in order to effectively deliver topics to the students. It is also necessary that the approach used by professors in the subject is not constructed into traditional classroom setting mode instead it should have an innovative and interesting combination of techniques. However, even with this kind of approach, students will still feel disinterest in the lesson. This was because they find no excitement beyond the boundaries. This inadequacy is due to a cause which the researchers would want to take notice of.

There is indeed a great necessity for a research that would awaken the consciousness of professors and the department in general, to find ways on how to deal with the adversities that opposes the competence of the science education curriculum in the tertiary level. Among the problems enumerated were defect in curriculum, and lack of exposure in laboratory activities that would provide better foundation to our student-teacher practitioners. These problems should not be tolerated, due to global competition. This results to the necessity to innovate.

It is in this light that the researchers will attempt to determine the probability of making the reconstruction of the science curriculum in UNC, in order to give attention to the resolve the issues of incompetency and find ways to address the situation. Finally, the researchers are anticipating that the administrators of UNC, be interested in meeting the needs of the science education curriculum students to be able to have graduates, students, and practitioners who are competitive based on the standards set by national accredited institutions. They may be willing to find new ways to improve the science education curriculum in UNC through the analyses conducted in this study, and find ample measures to address the issues and concerns that produce a relatively low number of enrolees.

The main objective of this study is to analyse the current science education curriculum of the College of Education in terms of its strengths, weaknesses, opportunities, and threats it has, as perceived by science instructors and students. The focus will be on the science education curriculum only. Also, this study will only be concerned with the perception of students specializing in science who are currently in their practice teaching this 1 st semester s/y 2015-2016. Furthermore, this study will not be concerned with any comparative analysis to other specializations in Bachelor of Secondary Education. This study was conducted to investigate the strengths, weaknesses, opportunities and threats of the tertiary science education curriculum in the University of Nueva Caceres as perceived by the science teachers and students.

\section{Literature Review}

Problems in Basic Science Education of this country showed that there was something wrong with our science syllabus, there were fewer topics in the science syllabi of countries with high achievement in The Trends in International Mathematics and Science Study (TIMSS), the series of international assessments of the mathematics and science knowledge of students around the world; and indicated that science and mathematics were more difficult subjects for the students [1][2][3].

Science instructional objectives must be stated in behavioural terms, which mean that they must be easily observable and measurable. Students should gain new knowledge which they can apply in explaining the occurrence of events [4][5]. That's why we have the SMART which is Specific, Measurable, Attainable, Relevant, and Time-Bound which we can apply in the teaching process. If the teacher brings the task to the 
understanding of students, broad knowledge of actual science materials and willingness to let the students observe and experiment [6]. We all know that science is the study of facts, that's why students must be observable, and students must know doing the experiment.

The teacher's role is to recognize, direct, guide, help, and support the inquiry cognitive activity of students because they are the centre of educational process [7][8]. Teachers should apply some Strategies of teaching wherein during the lesson proper students must know the topic. In all areas of Science, both Physical and Biological, there is a large repertoire of objects, places, and projects that a science teacher can explore and include in planning a science unit [4][7]. The key is careful planning and strict implementation of an activity in order to accomplish the objectives set. Noticed that today it is becoming more and more accepted that the chief aim of science education varies not from the chief aim of fundamental and general education [9][10]. Science is taught mainly not because of the importance of knowing and mastering science information parse, but because it is a must effective and appropriate way for building up the competencies that efficient citizen in a democracy must possess.

In society that is scientifically and technologically oriented as ours today, all students should be broadly educated in science and technology, in its process and impact in society [11][12]. The article further stated that the single most important goal of science education must produce scientifically literate citizen for a better understanding not just of themselves but of the world in which they inhabit. The pedagogical approach made the teacher a facilitator of learning experiences involving students as active participants [10][13][14]. Teachers must be a good role model to the students in order that students must be participating in discussion. The keys to a strong system of education are competent and effective teachers [15][16]. Education are Important to us wherein education can make us being a whole person. Schools with strong system of Education are also having a Good teacher.

\section{Methodology}

A qualitative research approach is proposed for this study. Qualitative approach is used through one-on-one interview, direct observation, and key-informant interview and journalizing. This study focused on six (6) participants; three (3) science professors and three students. The teachers were also considered as the key informant. The participants were identified through their direct relationship with the study and through referrals and suggestions. Three methods were in the data gathering process: interviews supplemented with data by key informants, non-participant observation and document reviews.

Interview was time-consuming, but was the main data-gathering method. A series of one-on-one interview with the participants were conducted to obtain responses on the effectiveness of science curriculum in the UNC through the identification of strengths, weaknesses, opportunities, and threats. Field observation was done with the observer role being supplementary to the interviewer role. With this, additional information that was observed stacked up against what was said in interviews. It was done through observation and inventory of materials, equipment, apparatuses, and procedures used in teaching the subjects to students specializing in science. Furthermore, feedbacks from other institutions through personal observations and friendly comments were also given emphasis in order to arrive at a sort of a comparative analysis of the science program.

The main document used for documentary review was the science education curriculum used by students. The researchers conducted an in-depth analysis of the curriculum and gathered the results in order to see the defects and missing considerations based on the student's perceived needs. The data analysis performed by the researchers was SWOT Analysis. This is a type of examination wherein an observer will gather important information regarding the strengths, weaknesses, opportunities, and threats of a particular topic in issue; eventually assessing its effectiveness and operational value. This data analysis method was chosen by the researchers in order to give a fair approach to the treatment of the science education curriculum. 


\section{Result and Discussion}

The six interviewees were considered as source of information wherein pertinent data to be categorized shall come from. Each participant was given four sets of questions strategically categorized as strength, weakness, opportunities, and threats. However, the participants were not obliged to answer all four sets of questions to practice truthfulness in the presentation of data in this study. Upon categorization, the results were as follows:

\section{Strengths of the science curriculum}

- Activities promoting independence were given to students

- Basic laboratory equipment, apparatuses, and instructional materials were complete

- Students gaining enough experiences to use as they become future professional teacher.

- Ability to take risks and strategize were taught to the students.

- Hands-on activities on major subjects like Chemistry, Physics and Biology were given.

- There was congruency to the Basic Education requirement

- Foundation was enough for the development of lessons / learning's.

Of the six persons interviewed, all were able to identify at least, one (1) response for each category. Table 1 shows the responses of the participants in terms of the strength. It was found out that the tertiary science curriculum in UNC provided good foundations to aid the students in learning. Aligned to the Basic Education requirement, the tertiary science education curriculum in the university can be considered strong.

\section{Weaknesses of science curriculum}

- Insufficiency of given activities

- Non-working / malfunctioning laboratory equipment

- Insufficient subjects in the curriculum

- Non-utilization of laboratory equipment, apparatuses, and instructional materials

- Absence of specific mathematics subject as required in the study of Physical Science which was greatly needed in the application for physical problem solving.

- Pre-requisite science and mathematics skills are not fully developed among science majors thus activities are streamlined to their capacity and readiness.

Those presented the weaknesses of the science education curriculum. Accordingly, the weaknesses enumerated by the participants were basically administration and academic-related. Insufficiency of activities, malfunctioning equipment, non-utilization of equipment, insufficiency of subjects, were among the academicrelated weaknesses of the current science education curriculum.

\section{Threats in science curriculum}

- Difficulty on the part of the professors to make students derive formulas which are needed to solve physical science problems that would tend to enhance a higher order thinking skill due to lack of Mathematics subject prerequisites

- Advanced and challenging activities cannot be fully introduced owing to the lack of requirements / instructional materials

- The need to specialize in all branches of science under the K-12 program.

Those showed the threats to the science education curriculum as perceived by students and teachers in science. Results gathered were observed in the current curriculum and mostly involved incompetency to produce a desired satisfaction level of students. It can be inferred that there is indeed a need to modify the curriculum for the students to fully learn and to adjust to the demands of the K-12 curriculum.

\section{Opportunities in science curriculum}

- The presence of the E-Library which will suffice the needs of the students in resource finding 
- Enhanced curriculum and effective models from other universities could be adopted.

Key informants stated their own personal perception on the opportunities of the science curriculum. Data is presented on Table 4. To effectively improvise the tertiary science curriculum of UNC, there is a need upgrade current innovations and integrate possibilities of opening up its doors to relations with other universities.

\section{Conclusion and Recommendation}

Result of interviews conducted and observation of researchers were consolidated to come up with the summary of findings, arrive at conclusions, and propose workable recommendation.

Analysis of the strengths and weaknesses of the science curriculum suggests that it still has benefits on the part of the students and professors but also has concerns that needed to be addressed immediately including: the use of laboratory equipment, apparatuses and instructional materials, and the inability of the current curriculum to expand its boundaries to other sciences rather it just focused on specific specializations. The science education curriculum of UNC is not aligned to what is required by the K-12 curriculum in terms of teacher preparation. Because of the predominant effect of K-12 educational system of the DepEd, there is a great need to modify the curriculum in science by promoting a general science curriculum to include all disciplines related to science.

Advanced and challenging activities cannot be fully introduced owing to the lack of requirements needed. Teachers are limited to implement the CHED approved curriculum despite not being able to address the demands/preparations required of K-12 secondary science teachers. The science education curriculum in UNC affects the general performance of teachers to effectively instruct the students due to failure of the curriculum to integrate related disciplines connected to the Physical Science such as Mathematics. The science curriculum also imposes a limitation of probable learning due to the lack of requirement needed for some activities. The College of Education in the university should conduct a curriculum review to be able to bridge the connections among subjects to be offered after considering the needs of the students and the demands of the K-12 curriculum. Though already patterned with CHED requirements, it is necessary that the department should improve considering the best interest of the school's clientele.

The main problems that students and instructors face in teaching science are lack of laboratory equipment and apparatuses, and instructional materials, insufficiency of subjects that must be included in the curriculum, malfunctioning or non-working equipment, non-developed science and mathematics skills of students owing to restraint the curriculum. There exists problems that affect the productivity of the students both performance and skills-related. Adjustments to the needs of the students must be done by providing them the needed instructional materials, apparatuses and laboratory equipment especially in higher Science subjects since most of the time students are exposed to laboratory activities.

The opportunities for improved level of effectiveness were maintaining the services of the E-library, and enhancing the curriculum by adopting and adapting the models from other universities. There are ways to improve the current level of effectiveness of tertiary science curriculum through integration of partnership possibilities with other universities and maintenance of current innovations. The recommendation are abolish specializations in the course offerings of the department, (e.g. Physical Science, Biological Science), rather, create a centralized course (e.g. General Science) to adapt with the spiral approach of K-12 curriculum of DepEd, establish a high practical involvement on the part of students to promote hands-on, minds-on experience incorporating research activities in the subject to contribute to high scientific thinking.

This study used an analytical approach in order to address the incompetence identified by the researchers. Thus, it can be inferred that this study will benefit the readers to have a concrete and definite understanding of the tertiary science curriculum in which they might be interested to enrol in. Besides such, this will also aid the administration and the College of Education in particular to re-evaluate the curriculum and propose measures for its improvement. The six interviewees were considered as source of information wherein pertinent data to be categorized shall come from. Each participant was given four sets of questions strategically categorized as strength, weakness, opportunities, and threats. 


\section{Acknowledgements}

Physics Education Department, Ahmad Dahlan University, Indonesia and Education Faculty, University of Nueva Caceres, Philippines for the cooperation on conduting this research.

\section{References}

[1] STACEY, Kaye. The PISA view of mathematical literacy in Indonesia. Journal on Mathematics Education, 2014, 2.02: 95-126.

[2] STEPHENS, Maria; SEN, Anindita. Comparing US States' Mathematics Results in PISA and Other International and National Student Assessments.Solsko Polje, 2014, 25.5/6: 87.

[3] SPARAPANI, Ervin F., et al. A global curriculum? Understanding teaching and learning in the United States, Taiwan, India, and Mexico. SAGE Open, 2014, 4.2: 2158244014536406.

[4] OBAOB, Geronimo S.; MONEVA, Jerald Cano-og. PERFORMANCE ASSESSMENT AND EVALUATION: MEASURING SUCCESS AND ACHIEVEMENT. European Scientific Journal, 2014, 10.31.

[5] MORTERA, Melvin O.; PAPA, Marilyn; FRANCISCO, Merlyn. Students' Acquired Skills in Filipino in the K-12 Program: Basis for Pedagogical Development. Imperial Journal of Interdisciplinary Research, 2016, 2.7.

[6] TIPPINS, Deborah J.; NEUHARTH-PRITCHETT, Stacey; MITCHELL, Debra. Connecting Young Children with the Natural World: Past, Present and Future Landscapes. In: Research in Early Childhood Science Education. Springer Netherlands, 2015. p. 279-297.

[7] SMART, Julie B.; MARSHALL, Jeff C. Interactions between classroom discourse, teacher questioning, and student cognitive engagement in middle school science. Journal of Science Teacher Education, 2013, 24.2: 249-267.

[8] KANG, Emily JS; BIANCHINI, Julie A.; KELLY, Gregory J. Crossing the border from science student to science teacher: Preservice teachers' views and experiences learning to teach inquiry. Journal of Science Teacher Education, 2013, 24.3: 427-447.

[9] TSENG, Chung-Hsien; TUAN, Hsiao-Lin; CHIN, Chi-Chin. How to help teachers develop inquiry teaching: Perspectives from experienced science teachers. Research in Science Education, 2013, 43.2: 809-825.

[10] ALLCHIN, Douglas; ANDERSEN, Hanne Møller; NIELSEN, Keld. Complementary approaches to teaching nature of science: integrating student inquiry, historical cases, and contemporary cases in classroom practice.Science Education, 2014, 98.3: 461-486.

[11] STUCKEY, Marc, et al. The meaning of 'relevance'in science education and its implications for the science curriculum. Studies in Science Education, 2013, 49.1: 1-34.

[12] BREINER, Jonathan M., et al. What is STEM? A discussion about conceptions of STEM in education and partnerships. School Science and Mathematics, 2012, 112.1: 3-11.

[13] WILLIAMS, John, et al. Promoting pedagogical content knowledge development for early career secondary teachers in science and technology using content representations. Research in Science \& Technological Education, 2012, 30.3: 327-343.

[14] SMITH, Susen. Differentiating teaching for sustainability for diverse student learning. In: Educating for Sustainability in Primary Schools. SensePublishers, 2015. p. 65-87.

[15] BYKER, Erik Jon; XU, Tingting; CHEN, Juan. Teacher Quality in the Twenty-First Century: Developing Globally Competent Teachers. In: Handbook of Research on Professional Development for Quality Teaching and Learning. IGI Global, 2016. p. 496-516.

[16] ANORICO, Heiden C.; VALDEZ, Les Paul; GAERLAN, Amelita A. Teachers' perspective on upward evaluation in basic education departments in Metro Manila. Studies in Educational Evaluation, 2016, 48: 43-56. 